\title{
Insulin Secretory Defects in Polycystic Ovary Syndrome Relationship to Insulin Sensitivity and Family History of Non-Insulin-dependent Diabetes Mellitus
}

David A. Ehrmann, * Jeppe Sturis, * Maria M. Byrne, * Theodore Karrison, * Robert L. Rosenfield, *‡ and Kenneth S. Polonsky*

Departments of ${ }^{*}$ Medicine and $\ddagger$ Pediatrics, University of Chicago, Chicago, Illinois 60637

\begin{abstract}
The increased prevalence of non-insulin-dependent diabetes mellitus (NIDDM) among women with polycystic ovary syndrome (PCOS) has been ascribed to the insulin resistance characteristic of PCOS. This study was undertaken to determine the role of defects in insulin secretion as well as familial factors to the predisposition to NIDDM seen in PCOS. We studied three groups of women: PCOS with a family history of NIDDM (PCOS FHx POS; $n=11$ ), PCOS without a family history of NIDDM (PCOS FHx NEG; $n$ $=13$ ), and women without PCOS who have a family history of NIDDM (NON-PCOS FHx POS; $n=8$ ). Beta cell function was evaluated during a frequently sampled intravenous glucose tolerance test, by a low dose graded glucose infusion, and by the ability of the beta cell to be entrained by an oscillatory glucose infusion. PCOS FHx POS women were significantly less likely to demonstrate appropriate beta cell compensation for the degree of insulin resistance. The ability of the beta cell to entrain, as judged by the spectral power for insulin secretion rate, was significantly reduced in PCOS FHx POS subjects. In conclusion, a history of NIDDM in a first-degree relative appears to define a subset of PCOS subjects with a greater prevalence of insulin secretory defects. The risk of developing NIDDM imparted by insulin
\end{abstract}

This study was presented in part at the 76th Annual Meeting of The Endocrine Society in Anaheim, CA on 15-18 June 1994.

Address correspondence to David A. Ehrmann, M.D., Department of Medicine, Section of Endocrinology, The University of Chicago Pritzker School of Medicine, 5841 South Maryland Avenue, MC 1027, Chicago, IL 60637. Phone: 312-702-9653; FAX: 312-702-9194; e-mail: dehrmann@medicine.bsd.uchicago.edu.

Received for publication 21 November 1994 and accepted in revised form 2 March 1995.

1. Abbreviations used in this paper: AIRg, first-phase insulin secretion; ANCOVA, analysis of covariance; AUCinsulin, area under the insulin response curve from 0 to $10 \mathrm{~min}$; AUCinsulin\%, AUCinsulin divided by one half the area under the insulin response curve from -20 to 0 min; BMI, body mass index; DHAS, dehydroepiandrosterone sulfate; $\mathrm{FSH}$, follicle-stimulating hormone; GnRH, gonadotropin-releasing hormone; $\mathrm{HbA}_{1}$, hemoglobin A1; IGT, impaired glucose tolerance; ISR, insulin secretion rate; IVGTT, intravenous glucose tolerance test; $\mathrm{LH}$, luteinizing hormone; NIDDM, non-insulin-dependent diabetes mellitus; NON-PCOS FHx POS, without PCOS and with a family history of NIDDM; OGTT, oral glucose tolerance test; PCOS, polycystic ovary syndrome; PCOS FHx NEG, with PCOS and without a family history of NIDDM; PCOS FHx POS, with PCOS and a family history of NIDDM; SHBG, sex hormone-binding globulin; $\mathrm{Si}$, sensitivity index.

J. Clin. Invest.

(C) The American Society for Clinical Investigation, Inc.

0021-9738/95/07/0520/08 \$2.00

Volume 96, July 1995, 520-527 resistance in PCOS may be enhanced by these defects in insulin secretion. (J. Clin. Invest. 1995. 96:520-527.) Key words: polycystic ovary syndrome • non-insulin-dependent diabetes mellitus • insulin secretion • insulin resistance • entrainment

\section{Introduction}

Women with polycystic ovary syndrome $(\mathrm{PCOS})^{1}$ are at increased risk of developing impaired glucose tolerance (IGT) and non-insulin-dependent diabetes mellitus (NIDDM) (110). $20 \%$ of obese women with PCOS develop IGT or frank NIDDM by age $40 \mathrm{yr}(3,11)$, and long-term follow-up of women with polycystic ovaries reveals an increased prevalence of NIDDM compared with controls $(9,10)$. This increased prevalence of IGT and NIDDM has been ascribed to the insulin resistance characteristic of the syndrome $(1-6,12)$. Because insulin resistance has been shown to antedate the onset of NIDDM in some studies (13-16), it has been postulated to be the primary pathogenetic factor in NIDDM. The high prevalence of NIDDM in women with PCOS is therefore consistent with similar findings in other populations in which insulin resistance is common $(14,16)$. On the other hand, this formulation of the pathophysiology of NIDDM in women with PCOS does not explain the observation that only a subset of these insulin-resistant women develop NIDDM. Defects in insulin secretion as well as familial and environmental factors must therefore also be considered as possible components in the predisposition to NIDDM seen in PCOS.

We have previously shown that insulin secretory responses to meals in insulin-resistant women with PCOS are reduced relative to basal insulin secretion (8), an alteration characteristic of NIDDM (17). In contrast, the acute ("first-phase") insulin response to intravenous glucose administration, another measure of beta cell function, has been reported to be normal in PCOS $(12,18)$.

The current study was therefore undertaken in an attempt to determine whether insulin secretory abnormalities are more common in a particular subset of insulin-resistant women with PCOS. The experimental design was modified to differentiate this study from our previous work and from other studies $(8$, $12,18,19)$. Insulin secretion was evaluated in relation to two factors known to be important in the development of NIDDM, namely, the presence or absence of a family history of NIDDM and the degree of insulin resistance. We were thus able to test the hypothesis that insulin secretory abnormalities, when viewed in relation to the degree of insulin resistance, are more common in women with PCOS who have a first-degree relative with NIDDM than in women with PCOS without such a family history.

\section{Methods}

\section{Subjects}

24 women with PCOS and 8 normal women volunteers were studied. They were divided into three groups as follows: women with PCOS 
with a first-degree relative (parent) with NIDDM (PCOS FHx POS; $n$ $=11$ ), women with PCOS without a family history of NIDDM (PCOS FHx NEG; $n=13$ ), and normal women with a first-degree relative with NIDDM (NON-PCOS FHx POS; $n=8$ ).

Women with PCOS had a history of infertility, oligomenorrhea/ anovulation (cycle lengths $>35 \mathrm{~d}$ ), hirsutism, or acne plus hyperandrogenemia (plasma free testosterone $>34.6 \mathrm{pmol} / \mathrm{liter}$ ) (20). The ovarian hyperandrogenism of PCOS was characterized by the presence of an abnormal 17-hydroxyprogesterone response to gonadotropin-releasing hormone (GnRH) agonist (nafarelin) administration and/or a supranormal plasma free testosterone level after administration of dexamethasone as previously reported (20). The results of these two tests are highly concordant and reflect related aspects of ovarian androgenic function (20).

Normal volunteers had regular menstrual cycles, lacked hirsutism or acne, and had normal plasma concentrations of both total and free testosterone as well as dehydroepiandrosterone sulfate (DHAS). Exclusion criteria included the use of medications known to alter insulin secretion and/or action within 2 mo of study, including glucocorticoids and oral contraceptives, and endocrinopathies, including nonclassic 21hydroxylase deficiency congenital adrenal hyperplasia, Cushing's syndrome, hyperprolactinemia, or thyroid dysfunction. A negative screening pregnancy test was required.

The racial/ethnic composition of the study subjects was representative of that of women attending the clinics: $41 \%$ were Caucasian, $50 \%$ African-American, and $9 \%$ were Asian. The protocols described in the following section were approved by the Institutional Review Board of the University of Chicago. Written informed consent was obtained from each subject.

\section{Experimental protocols}

Studies were performed after an overnight fast. Intravenous catheters were placed into antecubital veins. When appropriate, one catheter was used for administration of intravenous glucose or other secretagogues, and the catheter in the contralateral forearm was used for blood sampling. The blood sampling arm was heated to obtain arterialized venous samples.

GnRH agonist test. Hyperandrogenic women were studied in the follicular phase (days 1-8) of the cycle or after 2 or more months of amenorrhea. Blood samples were obtained before and at 16,20 , and 24 $\mathrm{h}$ after $100 \mu \mathrm{g}$ of nafarelin ([6-D-(2-naphthyl)-alanine]-GnRH acetate; Syntex Research, Palo Alto, CA) was administered as a subcutaneous injection as previously described (20). Serum luteinizing hormone (LH) and follicle-stimulating hormone (FSH) were measured every $20 \mathrm{~min}$ for $1 \mathrm{~h}$ (baseline) before nafarelin administration. The response to $\mathrm{GnRH}$ agonist administration was considered abnormal if the mean of the plasma 17-hydroxyprogesterone obtained at 16,20 , and $24 \mathrm{~h}$ exceeded the 95 th percentile of 23 previously studied normal volunteers (5.1 nmol/liter) (21).

Dexamethasone androgen suppression test. Plasma concentrations of total and free testosterone, sex hormone-binding globulin (SHBG), and DHAS were measured before and after administration of dexamethasone $(0.5 \mathrm{mg}$ four times daily for $4 \mathrm{~d}$ ); the second blood sample was obtained at $0800 \mathrm{~h}$ on day 5 . Dexamethasone suppression of androgen was considered abnormal if the plasma free testosterone concentration remained elevated ( $\geq 27.7 \mathrm{pmol} / \mathrm{liter}$ ) in the presence of normal adrenocortical suppression (20).

Oral glucose tolerance test. Glucose tolerance after ingestion of 75 $g$ of glucose was evaluated by an oral glucose tolerance test (OGTT) after an overnight fast using the criteria of the National Diabetes Data Group (22)

Frequently sampled intravenous glucose tolerance test. A frequently sampled intravenous glucose tolerance test (IVGTT) was performed as described by Bergman et al. (23). To account for the impact of sex steroids upon insulin sensitivity $(24,25)$, all subjects were studied in the follicular phase of the menstrual cycle or after at least 2 mo of amenorrhea. Blood samples for glucose and insulin were obtained every $5 \mathrm{~min}$ for $25 \mathrm{~min}$, at which time $0.3 \mathrm{~g} / \mathrm{kg}$ glucose was administered as an intravenous bolus. Blood was obtained at 2, 3, 4, 5, 6, 8, 10, 12, 14 ,
16 , and $19 \mathrm{~min}$. At time $20 \mathrm{~min}$, intravenous tolbutamide $\left(125 \mathrm{mg} / \mathrm{m}^{2}\right.$; Orinase; The Upjohn Co., Kalamazoo, MI) was administered. Thereafter, blood was sampled at $22,24,25$, and $27 \mathrm{~min}$, with subsequent sampling every $10 \mathrm{~min}$ from 30 to $100 \mathrm{~min}$ and then every $20 \mathrm{~min}$ from 100 to $180 \mathrm{~min}$.

Graded intravenous glucose infusion. A low dose graded glucose infusion protocol designed to determine beta cell responsiveness over the physiologic range of plasma glucose concentrations was performed as previously described (26). Briefly, to investigate insulin secretory responses at the lower end of the dose-response curve, each study began with the intravenous administration of a small bolus of insulin $(0.007 \mathrm{U} / \mathrm{kg})$. The administration of insulin at this dose to lower the fasting glucose does not affect subsequent insulin secretory responses (27). After a 20-min period during which the exogenously administered insulin was allowed to decay, blood samples were drawn at 10-min intervals for $30 \mathrm{~min}$ to define baseline levels of glucose, insulin, and C-peptide. A graded intravenous infusion of $20 \%$ dextrose was then started at a rate of $1 \mathrm{mg} / \mathrm{kg} / \mathrm{min}$ for $40 \mathrm{~min}$, followed by 2, 3, 4, 6, and $8 \mathrm{mg} / \mathrm{kg} / \mathrm{min}$, each for $40 \mathrm{~min}$. Blood samples were drawn at 10,20 , 30 , and $40 \mathrm{~min}$ into each period for measurement of glucose, insulin, and C-peptide.

Insulin secretory responses to oscillatory glucose administration. We have previously demonstrated that the peripheral administration of glucose in an oscillatory pattern results in regular oscillations in plasma glucose $(19,28)$. In normal subjects the beta cell is able to detect and respond to the repetitive increases and decreases in glucose with parallel changes in insulin secretion $(19,28)$. This adjustment of the insulin secretory oscillations to the glucose oscillations is termed entrainment. Lack of entrainment by glucose is an early manifestation of beta cell dysfunction in individuals with impaired glucose intolerance and mild diabetes (19).

To determine whether women with PCOS demonstrate defects in the ability of the beta cell to be entrained, a $20 \%$ glucose solution was administered in an oscillatory pattern with a period of $144 \mathrm{~min}$. This period is $20 \%$ longer than the endogenous period observed in normal subjects during constant glucose infusion (28) and most effectively brings out defective entrainment of pulsatile insulin secretion by glucose in states of impaired glucose tolerance (19). Glucose was administered for $16 \mathrm{~h}$ via a computer-controlled pump. Each oscillation was shaped as a sine wave with the amplitude being $33 \%$ above and below the mean infusion rate of $6 \mathrm{mg} / \mathrm{kg}$ body weight per minute. After allowing glucose to equilibrate during the initial $4 \mathrm{~h}(28,29)$, samples were drawn every $15 \mathrm{~min}$ for the remaining $12 \mathrm{~h}$ for the measurement of glucose, insulin, and C-peptide.

\section{Assay methods}

Plasma glucose was measured immediately using a glucose analyzer (YSI model 2300 STAT; Yellow Springs Instruments Co., Yellow Springs, $\mathrm{OH})$. The coefficient of variation of this method is $<2 \%$. Serum insulin was assayed by a double antibody technique (30) with a lower limit of sensitivity of $20 \mathrm{pmol} /$ liter and an average intraassay coefficient of variation of $6 \%$. The cross-reactivity of proinsulin in the radioimmunoassay for insulin is $\sim 40 \%$. Plasma C-peptide was measured as previously described (31). The lower limit of sensitivity of the assay is $0.02 \mathrm{pmol} / \mathrm{ml}$, and the intraassay coefficient of variation averaged $6 \%$. Hemoglobin $\mathrm{A} 1\left(\mathrm{HbA}_{1}\right)$ was measured by affinity chromatography (Glyc-Affin GHb kit; Isolab, Inc., Akron, $\mathrm{OH}$ ). The intraand interassay coefficient of variation is $3 \%$. Serum LH and FSH concentrations were measured using antisera and highly purified standards provided by the National Hormone and Pituitary Program in polyclonal radioimmunoassays with enhanced specificity for bioactive species (32). In our assay, $1.0 \mathrm{ng}$ of $\mathrm{LH} \mathrm{I}-2$ is equivalent to $7.8 \mathrm{IU}$, and 1.0 ng of FSH I-3 is equivalent to 3.9 IU in a multi-laboratory quality control program. The midrange coefficient of variation averages $5 \%$ intraassay and $12 \%$ interassay. The sensitivity of these assays averages $0.1 \mathrm{ng} / \mathrm{ml}$. Plasma concentrations of testosterone and DHAS were measured using kits obtained from Diagnostic Products Corp. (Los Angeles, CA) and Diagnostic Systems Laboratories, Inc. (Webster, TX). The 
free fraction of plasma testosterone was measured by a competitive protein binding (33). The concentration of SHBG binding was measured by a competitive protein binding assay as previously described (34). The intra- and interassay coefficients of variation were $3.8 \%$ and $8.7 \%$, respectively. The radioimmunoassay for 17 -hydroxyprogesterone was performed after chromatographic purification, as previously reported (32). The interassay precision of this assay approximates $12 \%$.

\section{Data analysis and statistical methods}

Summary measures derived from IVGTT. Summary measures derived from the IVGTT included the following: $(a)$ The baseline insulin concentration (mean of values at $-20,-15,-10,-5$, and $0 \mathrm{~min}$ ); (b) the area under the insulin response curve from time 0 to $10 \mathrm{~min}$ (AUCinsulin); $(c)$ the insulin response to glucose expressed as percent rise (AUCinsulin\%: area under the insulin response curve from time 0 to 10 min divided by one half the area under the insulin response curve from time -20 to $0 \mathrm{~min}$ ); (d) the first-phase insulin secretion (AIRg) in response to glucose calculated as the mean increment above basal of insulin values measured at 2, 3, 4, 5, 6, 8, and $10 \mathrm{~min} ;(e)$ the insulin sensitivity index $(\mathrm{Si})$, calculated using the MINMOD program provided to us by Dr. R. N. Bergman (University of Southern California) (23, 35 ). The Si represents the increase in net fractional glucose clearance rate per unit change in plasma insulin concentration after the intravenous glucose load; $(f)$ intravenous glucose tolerance expressed as the glucose disappearance constant, calculated as the slope of the least-squares regression line relating the natural logarithm of the glucose concentration to time between 10 and $19 \mathrm{~min}$ after glucose administration; and $(\mathrm{g})$ the relationship between the acute insulin response to glucose (AIRg) and the degree of insulin resistance $(\mathrm{Si})$. This relationship is calculated from the equation $\left.\mathrm{Z} \alpha=\left\{\ln \left[\left(\mathrm{Si} \times 10^{-5}\right) \times \mathrm{AIRg}\right)\right]+3.802\right\} / 0.5613$, which defines the relationship for these parameters in normal subjects (36). The percentile ranking based on the value of $Z \alpha$ is obtained from the table of the standard normal distribution.

Determination of insulin secretion rates. Standard kinetic parameters for C-peptide clearance were used to derive insulin secretory rates (ISRs). These standard parameters were calculated from 200 decay curves of biosynthetic C-peptide obtained in normal, obese, and NIDDM subjects (37). Age, sex, and body surface area were taken into account. These parameters were derived by application of a two-compartmen model of C-peptide distribution as proposed by Eaton et al. (38). These parameters were used to derive, in each 15-min interval between blood sampling, the ISR from the plasma C-peptide concentrations by deconvolution as previously described (39). The C-peptide profiles were smoothed with a two-point moving average before the calculation of the ISRs.

Relationship between glucose and ISR derived from graded glucose infusion. Baseline glucose, insulin, C-peptide, and ISR were calculated as the average of the four baseline samples, the first of which was drawn $20 \mathrm{~min}$ after insulin administration. During each glucose infusion period, average glucose and ISR were calculated. Mean ISR for each period was then plotted against the corresponding mean glucose level, thereby establishing a dose-response relationship. Because insulin secretion is best viewed in relation to the degree of insulin resistance (36), the product of $\mathrm{Si}$ and the mean ISR for each glucose infusion period was also plotted against the corresponding mean glucose level.

The average rate of insulin secreted over each sequential $1 \mathrm{mmol} /$ liter glucose concentration interval from 5.0 to $9.0 \mathrm{mmol} / \mathrm{liter}$ was calculated as the area under the curve for each interval using the trapezoidal rule. This area was then divided by $1 \mathrm{mmol} / \mathrm{liter}$ to obtain the correct units (picomoles per minute).

Spectral analysis. Each individual ISR and glucose profile from the oscillatory glucose infusion protocol was submitted to spectral analysis to determine whether the insulin oscillations were entrainable as previously reported $(40,41)$. Each spectrum was normalized assuming the total variance of each series to be $100 \%$ and is expressed as the normalized spectral power. Slow trends were removed by the first difference filter before each spectrum was calculated with the window closing procedure using a Tukey window with a width of 24 data points as described by Jenkins and Watts (41).
Table I. Clinical, Hormonal, and Metabolic Characteristics of Study Subjects

\begin{tabular}{|c|c|c|c|}
\hline & $\begin{array}{c}\text { PCOS } \\
\text { FHx POS }\end{array}$ & $\begin{array}{c}\text { PCOS } \\
\text { FHx NEG }\end{array}$ & $\begin{array}{l}\text { NON-PCOS } \\
\text { FHx POS }\end{array}$ \\
\hline No. subjects & 11 & 13 & 8 \\
\hline Age (yr) & $25.2 \pm 5.8^{*}$ & $26.8 \pm 4.9$ & $32.0 \pm 2.3$ \\
\hline BMI $\left(\mathrm{kg} / \mathrm{m}^{2}\right)$ & $35.6 \pm 11.3$ & $31.5 \pm 10.9$ & $35.2 \pm 5.5$ \\
\hline Waist/hip ratio & $0.82 \pm 0.09$ & $0.85 \pm 0.07$ & $0.90 \pm 0.06$ \\
\hline $\mathrm{HbA}_{1}(\%)$ & $5.9 \pm 0.8$ & $5.5 \pm 0.4$ & $6.0 \pm 0.7$ \\
\hline LH (IU/liter) & $21.0 \pm 12.2$ & $19.1 \pm 5.6$ & - \\
\hline FSH (IU/liter) & $4.5 \pm 1.3$ & $5.9 \pm 2.2$ & - \\
\hline LH/FSH & $4.7 \pm 2.0$ & $3.5 \pm 1.4$ & - \\
\hline SHBG (nM) & $11.9 \pm 11.4^{*}$ & $16.5 \pm 12.0$ & $29.1 \pm 11.5$ \\
\hline \multicolumn{4}{|l|}{ Free testosterone $(\mathrm{pM})$} \\
\hline Pre-dexamethasone & $173 \pm 104 * \pm$ & $87 \pm 35$ & $21 \pm 7$ \\
\hline Post-dexamethasone & $90 \pm 35$ & $59 \pm 24$ & - \\
\hline $\begin{array}{l}\text { 17-Hydroxyprogesterone } \\
\text { (nmol/liter; 16-24 h } \\
\text { mean) }\end{array}$ & $15.6 \pm 5.3^{\ddagger}$ & $9.5 \pm 4.0$ & - \\
\hline \multicolumn{4}{|l|}{ OGTT } \\
\hline \multicolumn{4}{|l|}{ Basal glucose (mmol/ } \\
\hline liter) & $4.9 \pm 0.7$ & $4.6 \pm 0.4$ & $5.0 \pm 0.4$ \\
\hline 2-h glucose (mmol/liter) & $7.3 \pm 1.8$ & $6.3 \pm 1.7$ & $7.0 \pm 1.3$ \\
\hline \multicolumn{4}{|l|}{ IVGTT } \\
\hline Basal insulin (pM) & $265 \pm 222$ & $179 \pm 196$ & $127 \pm 51$ \\
\hline $\mathrm{Si}\left(10^{-5} \mathrm{~min}^{-1 / p M}\right)$ & $2.2 \pm 3.0$ & $3.8 \pm 3.0$ & $2.6 \pm 3.2$ \\
\hline AIRg (pM) & $574 \pm 520$ & $1397 \pm 1682$ & $688 \pm 500$ \\
\hline AUCinsulin & $7502 \pm 6009$ & $15015 \pm 17535$ & $8310 \pm 5074$ \\
\hline AUCinsulin\% & $419 \pm 238^{\ddagger}$ & $1011 \pm 484$ & $798 \pm 542$ \\
\hline $\begin{array}{l}\text { AIRg vs. Si (percentile } \\
\text { rank) }\end{array}$ & $8 \pm 11^{\ddagger}$ & $33 \pm 21$ & $19 \pm 17$ \\
\hline \multicolumn{4}{|l|}{ Normalized spectral power } \\
\hline ISR & $5.8 \pm 3.9^{\ddagger}$ & $10.5 \pm 4.8$ & $9.7 \pm 4.4$ \\
\hline Glucose & $15.9 \pm 2.8$ & $16.5 \pm 3.2$ & $17.2 \pm 1.9$ \\
\hline
\end{tabular}

$P<0.05$ (ANOVA). * PCOS FHx POS vs. NON-PCOS FHx POS. ${ }^{\ddagger}$ PCOS FHx POS vs. PCOS FHx NEG.

Statistical analysis. The significance of differences between groups was determined using the unpaired $t$ test, ANOVA, or analysis of covariance (ANCOVA) with Scheffé's allowance for multiple comparisons as appropriate. For all analyses, a two-tailed $P$ value of $<0.05$ was considered to indicate statistical significance. Unless otherwise noted, all results are expressed as mean \pm SD. Data analysis was performed using StatView SE+Graphics and SuperANOVA for the Macintosh (Abacus Concepts, Inc., Berkeley, CA).

\section{Results}

\section{Clinical characteristics of study subjects}

Each study group comprised predominantly obese (body mass index $[\mathrm{BMI}]>27 \mathrm{~kg} / \mathrm{m}^{2}$ ) subjects (Table I). The ranges for BMI values among PCOS FHx POS, PCOS FHx NEG, and NON-PCOS FHx POS groups, respectively, were 22.4-58.1, $20.2-54.7$, and $26.2-40.1 \mathrm{~kg} / \mathrm{m}^{2}$. The mean BMI and waist/ hip ratios were similar for all three groups. PCOS FHx POS subjects did not differ from PCOS FHx NEG subjects by ethnic/ racial background, hirsutism score, presence of acne, acanthosis nigricans, or ovulatory status. 21 of $24(88 \%)$ PCOS subjects were anovulatory as defined by cycle lengths $>35 \mathrm{~d} ; 3$ (12\%) had regular menstrual cycles (menses every 28-32 d). There 
were no significant differences in measures of insulin secretion between anovulatory and ovulatory PCOS subjects (data not shown). As a group, PCOS subjects were younger than NONPCOS volunteers $(P<0.05)$.

Hormonal and metabolic characteristics of study subjects

Androgen and gonadotropin levels. The degree of androgen excess was greatest in PCOS FHx POS subjects. This is reflected in a significantly higher baseline level of free testosterone $(173 \pm 104$ vs $87 \pm 35 \mathrm{pM} ; P=0.01$ vs PCOS FHx NEG) and the 17-hydroxyprogesterone response to nafarelin (15.6 \pm 5.3 vs $9.5 \pm 4.0 \mathrm{nmol} /$ liter; $P=0.01$ vs PCOS FHx NEG). Levels of free testosterone after dexamethasone were not significantly different between the two PCOS groups. Although an elevated serum LH or LH/FSH ratio was not required for the diagnosis of PCOS (20), at least one of these findings was present in 18 of 24 (75\%) subjects.

Although there was no significant difference in the mean serum SHBG, LH, FSH, or LH/FSH ratio between the two PCOS groups to account for the observed differences in androgen concentrations (Table I), ANCOVA revealed a significant effect of SHBG on free testosterone levels $(P<0.03)$ and of the LH/FSH ratio on the 17-hydroxyprogesterone responses to nafarelin $(P<0.05)$. There was, in addition, a significant association $(r=0.48, P=0.02)$ between the LH/FSH ratio and the 17-hydroxyprogesterone response to nafarelin in PCOS subjects.

To determine whether the differences in levels of free testosterone or 17-hydroxyprogesterone could account for differences in beta cell function between groups, we performed an ANCOVA. The differences in measures of beta cell function between PCOS FHx POS and PCOS FHx NEG groups (see the following discussion) remained significant even after free testosterone and 17-hydroxyprogesterone levels were included in the ANCOVA model.

Level of glucose tolerance. All three groups had comparable indices of overall glucose tolerance. All subjects had $\mathbf{H b A}_{1}$ levels at or below the upper limit of normal (7.2\%). The plasma glucose concentrations at baseline and $2 \mathrm{~h}$ after a $75-\mathrm{g}$ oral glucose load did not differ between groups. None of the subjects in any group had a fasting plasma glucose concentration above normal (range: 3.7-6.0 mmol/liter). Although none of the subjects met criteria for IGT or NIDDM (22), 7 of 24 (29\%) PCOS subjects had indeterminate ("nondiagnostic") (22) OGTTs. Of note, these individuals were approximately equally distributed among those with $(n=4 ; 36 \%)$ and those without $(n=3$; $23 \%$ ) a family history of NIDDM. There was no significant effect of age upon $\mathrm{HbA}_{1}$, baseline, or 2-h glucose values. With the exception of one subject from each PCOS group, all subjects had normal intravenous glucose tolerance as reflected in a glucose disappearance constant $\geq 1.0$ (12).

\section{Responses during the frequently sampled IVGTT}

Basal insulin levels. Basal serum insulin levels obtained before administration of intravenous glacose were highly correlated with BMI ( $r=0.80, p=0.0001)$. Although not statistically significant, basal serum insulin levels tended to be higher in the PCOS subjects $(220 \pm 209 \mathrm{pM})$ than in NON-PCOS subjects $(127 \pm 51 \mathrm{pM}$ ) (Fig. 1). In turn, among women with PCOS, basal serum insulin levels tended to be slightly higher in those with a family history of NIDDM $(265 \pm 222$ vs $179 \pm 196)$, but again these differences were not statistically significant.

Insulin sensitivity and first-phase insulin secretory re-

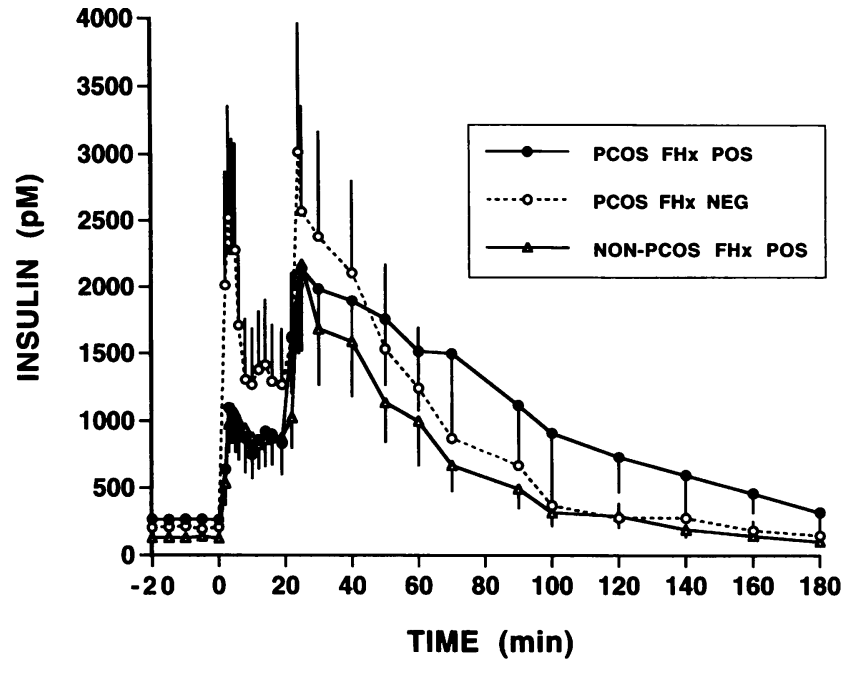

Figure 1. Mean ( \pm SE) serum insulin levels in PCOS FHx POS, PCOS FHx NEG, and NON-PCOS FHx POS subjects before ( -20 to $0 \mathrm{~min}$ ) and after intravenous administration of $0.3 \mathrm{~g} / \mathrm{kg}$ glucose. At time 20 min, tolbutamide $\left(125 \mathrm{mg} / \mathrm{m}^{2}\right)$ was administered as an intravenous bolus. The acute (first-phase) insulin response to intravenous glucose administration was significantly reduced in PCOS FHx POS subjects.

sponses to intravenous glucose. The three groups were similar in their degree of insulin resistance. Since the degree of adiposity is known to be a major determinant of insulin sensitivity (36), there was a highly significant inverse correlation between BMI and $\mathrm{Si}$ among all subjects $(r=-0.71, P=0.0001)$. The slope of this relationship was similar among subgroups. Although it has been reported that women with PCOS are more insulin resistant than normal subjects matched for BMI (6), we did not find this to be the case in our study subjects.

The acute insulin response to intravenous glucose administration was analyzed in absolute terms and in relation to both the baseline insulin level and the degree of insulin resistance. When the acute insulin response was expressed as the mean increment above baseline (AIRg) or as the area under the insulin curve (AUCinsulin), there was a tendency for a greater response among PCOS FHx NEG subjects, although these differences did not achieve statistical significance (Table I).

When the acute insulin response was calculated as the percent rise above the baseline level of insulin (AUCinsulin\%) or in relation to the magnitude of ambient insulin resistance (percentile rank for AIRg vs Si), group differences in beta cell function became significant. Specifically, PCOS subjects with a family history of NIDDM had first-phase insulin secretory responses that were significantly lower than responses in PCOS subjects without such a family history. These latter derived expressions of the data take into account the effects of basal hyperinsulinemia and insulin resistance, respectively, upon beta cell function (36).

\section{Responses to graded glucose infusion}

The relationship between glucose and ISR obtained during the graded glucose infusion protocol is depicted in Fig. 2 (upper panel). The absolute ISR at any given concentration of glucose achieved during the graded glucose infusion was similar between study groups. However, when the ISR was expressed in relation to the degree of insulin resistance (the product of ISR and $\mathrm{Si}$ ), the dose-response relationship appears to be shifted downward and rightward in PCOS FHx POS subjects when 

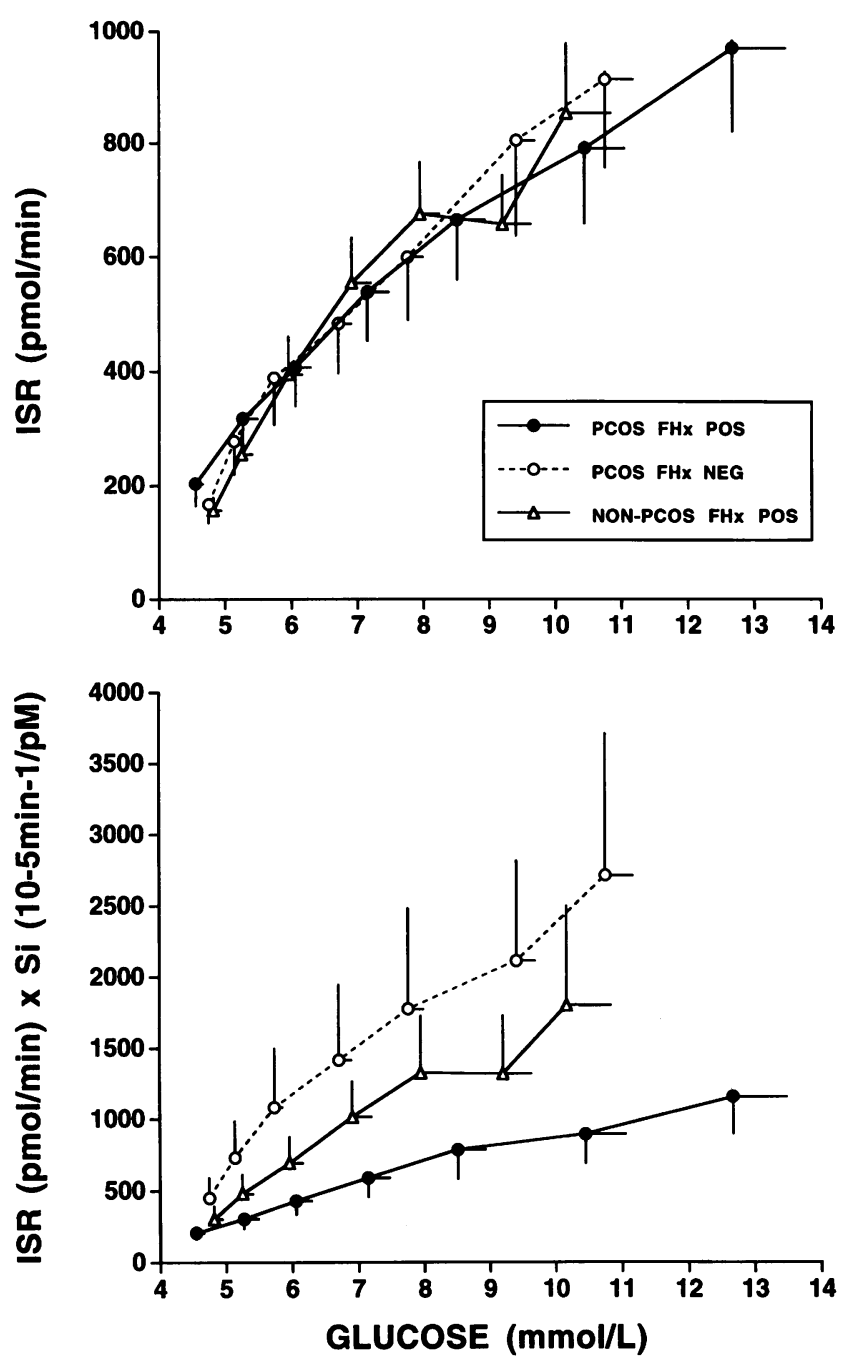

Figure 2. Relationship between glucose level and ISR (upper panel) and between glucose level and the product of ISR and Si (lower panel) during the graded glucose infusion protocol. The absolute ISR at any given concentration of glucose achieved during the graded glucose infusion was similar between study groups (upper panel). When the ISR is expressed in relation to the degree of insulin resistance, however, differences in the dose-response curves between groups become apparent (lower panel). Data are mean \pm SE.

compared with PCOS FHx NEG subjects (Fig. 2, lower panel). In addition, at the upper end of the physiologic glucose range (7.0-9.0 mmol/liter), PCOS FHx POS subjects secreted significantly less insulin, when expressed in relation to the degree of insulin resistance, than did PCOS FHx NEG subjects (Fig. 3).

\section{Responses to oscillatory glucose administration}

The ability of the oscillatory infusion of exogenous glucose to entrain insulin secretion was most impaired in PCOS subjects with a family history of NIDDM, as reflected in a significantly lower mean value for the normalized spectral power for ISR (Table I). This difference in the spectral power for ISR between groups does not appear to be the result of either hyperglycemia itself or insulin resistance, since the groups were similar with respect to both. In addition, the normalized spectral power for oscillations in plasma glucose resulting from the oscillatory glucose infusion was similar between groups and thus could

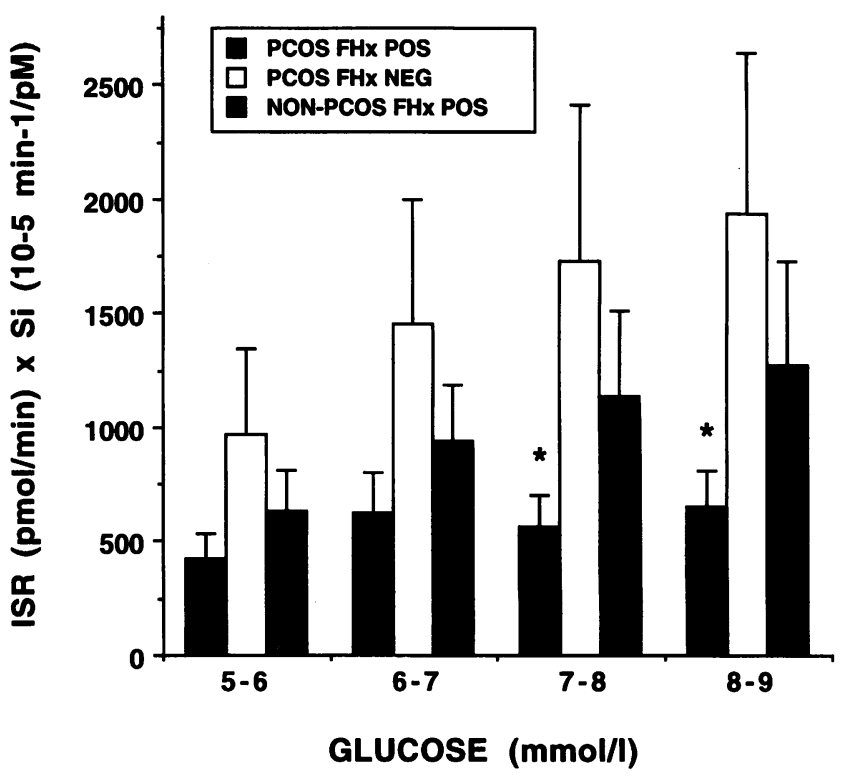

Figure 3. Product of average insulin secretion rates and Si for subjects over $1 \mathrm{mmol} /$ liter glucose intervals during graded glucose infusion. Data are mean \pm SE. $* P<0.05$ PCOS FHx POS vs PCOS FHx NEG.

not account for the difference in the normalized spectral power for ISR.

Fig. 4 depicts the profiles of glucose and ISR in response to the oscillatory glucose infusion in one representative $\mathrm{FHx}$ NEG PCOS and one representative FHx POS PCOS subject.

\section{Discussion}

The current study was undertaken to assess the prevalence of beta cell secretory abnormalities in women with PCOS and to examine their potential role in the predisposition that these subjects have to develop NIDDM. We hypothesized that insulin secretory abnormalities are more common in women with PCOS who have a first-degree relative with NIDDM than in women with PCOS without such a family history. Since defects in beta cell function are well established once IGT or NIDDM has developed (19), we studied three groups of subjects composed of individuals with normal or indeterminate glucose tolerance. These included women with PCOS who have a family history of NIDDM, women with PCOS without a family history of NIDDM, and women without PCOS who have a family history of NIDDM. Beta cell function was evaluated during the course of a frequently sampled IVGTT using modifications of the Bergman (23) minimal model and in response to a graded intravenous glucose infusion $(26,27)$. These methods permit assessment of the adequacy of the insulin response to intravenous glucose in both absolute terms and in relation to the degree of insulin resistance. In addition, we evaluated the ability of the beta cell to detect and respond appropriately to successive increments and decrements in the plasma glucose level provoked by oscillatory administration of glucose $(19,28)$.

We found that during a rapidly sampled IVGTT, women with PCOS have normal first-phase insulin secretion in absolute terms when compared with women without PCOS. This is consistent with observations of other investigators $(12,18)$. However, when first-phase insulin secretion was analyzed in relation to either the degree of insulin resistance or basal insulin secre- 

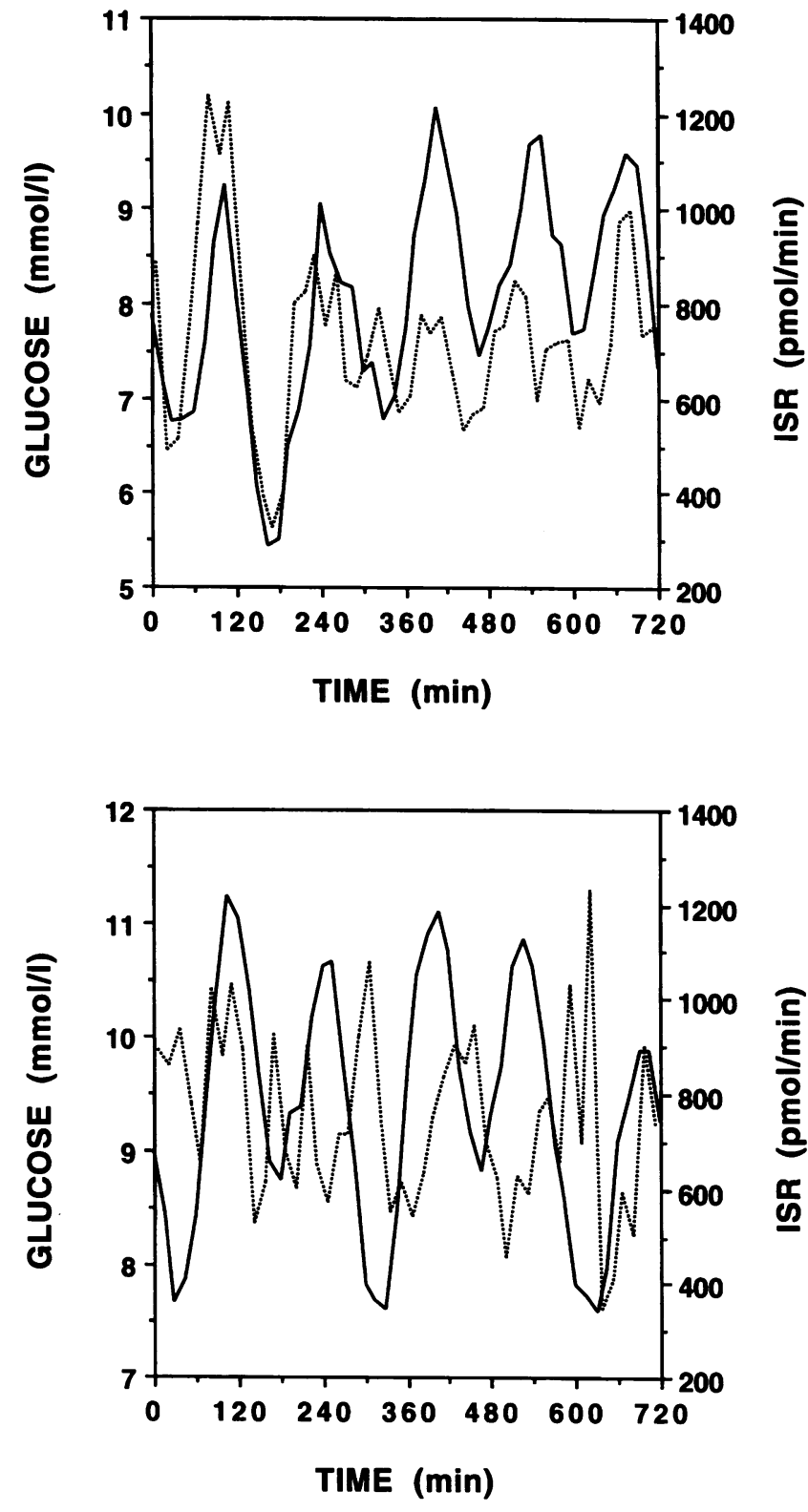

Figure 4. Profiles of the glucose concentrations (solid line) and ISR (dashed line) in response to an oscillatory glucose infusion in one representative PCOS FHx NEG (upper panel) and one representative PCOS FHx POS (lower panel) subject. Although the subjects were similarly insulin resistant (PCOS FHx NEG: $\mathrm{Si}=0.510^{-5} \mathrm{~min}^{-1} / \mathrm{pM}$; PCOS FHx POS: $\mathrm{Si}=0.110^{-5} \mathrm{~min}^{-1} / \mathrm{pM}$ ), they differed in their ability to entrain insulin secretion in response to the oscillatory glucose infusion. The difference in the subjects' ability to adjust insulin secretory oscillations in response to glucose oscillations is reflected in a normalized spectral power of 11.1 (PCOS FHx NEG) vs 4.1 (PCOS FHx POS).

tion, we found that women with PCOS who have a family history of diabetes were significantly more likely to demonstrate alterations in beta cell function. The results of the graded glucose infusion protocol were analogous to those of the IVGTT. The absolute ISR at any given concentration of glucose achieved during the graded glucose infusion was similar between study groups. However, PCOS FHx POS subjects had significantly lower rates of insulin secretion when expressed in relation to insulin sensitivity than did PCOS FHx NEG subjects, particu- larly at the upper end of the physiologic glucose range (Figs. 2 and 3 ). These findings are consistent with recent evidence that in individuals with reduced insulin sensitivity, a "normal" insulin response to intravenous glucose administration may be inappropriately low and therefore indicative of beta cell dysfunction (36). Specifically, when the product of the first-phase insulin responses to intravenous glucose and $\mathrm{Si}$ were ranked by percentile (36), the average value in the women with PCOS who had a family history of NIDDM $(8 \pm 11)$ was significantly lower than the value in PCOS women without a family history of NIDDM $(33 \pm 21)$. Similarly, the acute insulin response to intravenous glucose expressed in relation to basal insulin secretion (AUCinsulin\%) was significantly reduced in PCOS subjects with a family history of NIDDM $(419 \pm 238)$ compared with those without such a family history $(1011 \pm 484)$.

We also found that the ability of the beta cell to adjust and respond to oscillations in the plasma glucose level as judged by the spectral power for ISR was significantly reduced in the PCOS subjects with a family history of NIDDM (5.8 \pm 3.9$)$ compared with those without such a family history $(10.5 \pm 4.8)$ (Table I; Fig. 4). Prior studies had shown that the spectral power for ISR progressively declines with the transition from normal glucose tolerance to IGT to NIDDM (19). However, the observed difference in spectral power for ISR between groups cannot be explained by differences in insulin sensitivity or glucose tolerance, since our study groups were well matched in measures of both insulin sensitivity and glucose tolerance as reflected in the $\mathrm{HbA}_{1}$ concentrations and plasma glucose concentrations during OGTT. In addition, the spectral power for glucose during the oscillatory glucose infusion was similar between groups. Finally, although it has recently been reported that pulsatile insulin secretion is abnormal in abdominally obese subjects (42), this is unlikely to account for our findings since our three study groups were similar in body fat distribution as reflected in the waist/hip ratio.

What might account for our finding that PCOS subjects with a positive family history of NIDDM had higher androgen concentrations than comparison groups, and more importantly, could these higher androgen concentrations be responsible for the observed differences in beta cell function? Despite the fact that the SHBG concentrations and the LH/FSH ratios were not significantly different between PCOS FHx POS and PCOS FHx NEG groups, the differences in androgen concentrations between groups could be accounted for, at least in part, by the effects of SHBG and the LH/FSH ratio on levels of free testosterone and 17-hydroxyprogesterone, respectively, as revealed by ANCOVA. The differences in measures of beta cell function between PCOS FHx POS and PCOS FHx NEG groups remained significant, however, even after free testosterone and 17-hydroxyprogesterone levels were accounted for by ANCOVA. Finally, although insulin clearance is reduced in PCOS (8) and hepatic insulin extraction has been reported to be inversely correlated with serum androgen concentrations in women (43), there have been no reported direct effects of androgens upon beta cell function. Thus, if androgens were to have any effect on beta cell function, it might be indirectly by modulation of insulin resistance. Although androgen excess has been implicated as a cause of insulin resistance in PCOS (44), the majority of evidence indicates that insulin resistance is an intrinsic defect in PCOS that is independent of androgen excess (45). Despite the differences in androgen concentrations, our groups were similarly insulin resistant.

Could our findings be accounted for by group differences 
in age or BMI? It appears that beta cell function declines with age as assessed by spectral analysis of insulin secretion in response to an oscillatory glucose infusion (46). Although PCOS FHx POS subjects were younger than controls, their defects in beta cell dysfunction were greater. Thus, the differences in beta cell function that we observed are unlikely to be related to the effects of aging. In addition, ANCOVA did not reveal a significant impact of either BMI or age on measures of beta cell function.

Although the degree of insulin resistance has been reported to be greater in obese PCOS subjects than in controls of similar weight and fat-free body mass (3), such was not the case in our study subjects. This may have resulted from the fact that the majority of our subjects had a BMI $>30 \mathrm{~kg} / \mathrm{m}^{2}$. It has been suggested that the degree of variability for $\mathrm{Si}$ is greater in lean compared with obese subjects and that once BMI exceeds $30 \mathrm{~kg} / \mathrm{m}^{2}$, the development of further obesity is not predicted to result in a measurable decrease in $\mathrm{Si}$ (36).

Our results suggest that the risk imparted by insulin resistance to the development of NIDDM in PCOS may be enhanced by defects in insulin secretion. Furthermore, they suggest that a history of NIDDM in a first-degree relative defines a subset of PCOS subjects who may be at greatest risk for secretory defects. Our evidence that beta cell dysfunction in PCOS may have a familial basis is consistent with the finding that firstphase insulin secretion aggregates in families independent of the aggregation of insulin action $(13,47,48)$, as well as recent evidence that when insulin sensitivity is accounted for, normoglycemic first-degree relatives of patients with NIDDM have impairments in first-phase insulin secretion when compared with controls (49).

It has been suggested that early onset NIDDM (age 25-40 yr) may represent a distinct entity resulting from a codominant mode of inheritance of diabetogenic genes from both parents (50). It is possible that inheritance of putative diabetogenic genes from one or both parents of women with PCOS may underlie the abnormalities in beta cell function that are demonstrable at such an early age. Alternatively, it is possible that beta cell dysfunction is simply more apparent in PCOS in the presence of additional cofactors, such as a unique form of insulin resistance $(51,52)$. Additional studies are required to determine whether there is a genetic basis for defects in insulin secretion and action in PCOS.

In summary, we have obtained evidence using several independent methods that beta cell dysfunction in PCOS is demonstrable in the absence of impaired glucose tolerance. This is evidenced both by reduced insulin secretory responses either to boluses or graded infusions of intravenous glucose when expressed relative to the degree of insulin resistance and by the impairment in the ability to entrain endogenous insulin secretion with glucose. Such defects are most evident in PCOS subjects with a family history of NIDDM. Although it is known that evidence of beta cell dysfunction among insulin-resistant subjects is useful in predicting which subjects are likely to develop NIDDM (14), prospective studies with long-term follow-up will be required to determine whether this finding is applicable to women with PCOS.

\section{Acknowledgments}

The authors wish to thank Dr. Niall O'Meara for useful suggestions regarding study design and the nursing staff of the Clinical Research Center for expert care of the subjects who participated in the study. In particular, we wish to thank Jacqueline Imperial, R.N. The authors also greatly appreciate the technical contributions of Paul Rue and Marsha Jackson. Intravenous tolbutamide was kindly provided for these studies by The Upjohn Co.

These studies were supported in part by U. S. Public Health Service grants HD-06308, RR-00055, and DK 07011-17 and in part by Syntex Research. Dr. Sturis was supported by a Research Career Development Award from the Juvenile Diabetes Foundation International.

\section{References}

1. Burghen, G. A., J. R. Givens, and A. E. Kitabchi. 1980. Correlation of hyperandrogenism with hyperinsulinemia in polycystic ovarian disease. J. Clin Endocrinol. Metab. 50:113-116.

2. Chang, R. J., L. R. Laufer, D. R. Meldrum, R. M. Nakamura, H. L. Judd and S. A. Kaplan. 1983. Steroid secretion in polycystic ovary disease after ovarian suppression by a long-acting gonadotropin-releasing hormone agonist. J. Clin. Endocrinol. Metab. 56:897-903.

3. Dunaif, A., M. Graf, J. Mandeli, V. Laumas, and A. Dobrjansky. 1987. Characterization of groups of hyperandrogenic women with acanthosis nigricans, impaired glucose tolerance and/or hyperinsulinemia. J. Clin. Endocrinol. Metab. 65:499-507.

4. Jialal, I., R. P. Naike, K. Reddi, J. Moodley, and S. M. Joubert. 1987. Evidence for insulin resistance in nonobese patients with polycystic ovarian disease. J. Clin. Endocrinol. Metab. 64:1066-1069.

5. Dunaif, A., J. Mandeli, H. Fluhr, and A. Dobrjansky. 1988. The impact of obesity and chronic hyperinsulinemia on gonadotropin release and gonadal steroid secretion in the polycystic ovary syndrome. J. Clin. Endocrinol. Metab. 66:131139.

6. Dunaif, A., K. R. Segal, W. Futterweit, and A. Dobrjansky. 1989. Profound peripheral insulin resistance, independent of obesity, in polycystic ovary syndrome. Diabetes. 38:1165-1174.

7. Moller, D. E., and J. S. Flier. 1991. Insulin resistance-mechanisms, syndromes, and implications. N. Engl. J. Med. 325:938-948.

8. O'Meara, N. M., J. D. Blackman, D. A. Ehrmann, R. B. Barnes, R. L. Rosenfield, J. B. Jaspan, and K. S. Polonsky. 1993. Defects in beta cell function in functional ovarian hyperandrogenism. J. Clin. Endocrinol. Metab. 76:12411247.

9. Dahlgren, E., P. O. Janson, S. Johansson, G. Linstedt, A. Oden, N. Crona, F. Knutsson, L. A. Mattson, and P. A. Lundberg. 1992. Women with polycystic ovary syndrome wedge resected in 1956 to 1965: a long-term follow-up focusing on natural history and circulating hormones. Fertil. Steril. 57:505-513.

10. Dahlgren, E., L. Lapidus, P. O. Janson, G. Lindstedt, S. Johansson, and L. Tengborn. 1994. Hemostatic and metabolic variables in women with polycystic ovary syndrome. Fertil. Steril. 61:455-460.

11. Dunaif, A. 1992. Diabetes mellitus and polycystic ovary syndrome. In Current Issues in Endocrinology and Metabolism. Polycystic Ovary Syndrome. A. Dunaif, J. R. Givens, F. P. Haseltine, and G. R. Merriam, editors. Blackwell Scientific, Cambridge, MA. 347-358.

12. Holte, J., T. Bergh, C. Berne, L. Berglund, and H. Lithell. 1994. Enhanced early insulin response to glucose in relation to insulin resistance in women with polycystic ovary syndrome and normal glucose tolerance. J. Clin. Endocrinol. Metab. 78:1052-1058.

13. Martin, B. C., J. H. Warram, A. S. Krolewski, R. N. Bergman, J. S. Soeldner, and C. R. Kahn. 1992. Role of glucose and insulin resistance in development of type 2 diabetes mellitus: results of a 25 -year follow-up study. Lancet. 340:925-929.

14. Lillioja, S., D. M. Mott, M. Spraul, R. Ferraro, J. E. Foley, E. Ravussin E. C. Knowler, P. H. Bennett, and C. Bogardus. 1993. Insulin resistance and insulin secretory dysfunction as precursors of non-insulin-dependent diabetes mellitus. Prospective studies of Pima Indians. N. Engl. J. Med. 329:1988-1992.

15. Schumacher, M. C., S. J. Hasstedt, S. C. Hunt, R. R. Williams, and S. C. Elbein. 1992. Major gene effect for insulin levels in familial NIDDM pedigrees. Diabetes. 41:416-423.

16. Warram, J. H., B. C. Martin, A. S. Krolewski, J. S. Soeldner, and C. R. Kahn. 1990. Slow glucose removal rate and hyperinsulinemia precede the development of type II diabetes in the offspring of diabetic parents. Ann. Int. Med. 113:909-915.

17. Polonsky, K. S., B. D. Given, L. Hirsch, H. Tillil, E. T. Shapiro, C. Beebe B. H. Frank, J. A. Galloway, and E. Van Cauter. 1988. Abnormal patterns of insulin secretion in non-insulin dependent diabetes mellitus. N. Engl. J. Med. 318:1231-1239.

18. Dunaif, A., G. Green, and D. Finegood. 1992. Pancreatic beta (B) cell function is normal in insulin resistant women with the polycystic ovary syndrome (PCOS). Proc. Endocrine Soc., 74th Annual Meeting, San Antonio, TX. $280 a$ (Abstr.)

19. O'Meara, N. M., J. Sturis, E. Van Cauter, and K. S. Polonsky. 1993. Lack of control by glucose of ultradian insulin secretory oscillations in impaired glucose 
tolerance and in non-insulin-dependent diabetes mellitus. J. Clin. Invest. 92:262271.

20. Ehrmann, D. A., R. L. Rosenfield, R. B. Barnes, D. F. Brigell, and Z Sheikh. 1992. Detection of functional ovarian hyperandrogenism in women with androgen excess. $N$. Engl. J. Med. 327:157-162.

21. Ehrmann, D. A., M. Byrne, J. Sturis, R. L. Rosenfield, and K. S. Polonsky. 1994. $\beta$-Cell dysfunction in polycystic ovary syndrome (PCOS): evidence for a genetic basis. Proc. Endocrine Soc., 76th Annual Meeting, Anaheim, CA. $835 a$ (Abstr.)

22. National Diabetes Data Group. 1979. Classification and diagnosis of diabetes mellitus and other categories of glucose intolerance. Diabetes. 28:1039-1057.

23. Bergman, R. N., L. S. Phillips, and C. Cobelli. 1981. Physiologic evaluation of factors controlling glucose tolerance in man. Measurement of insulin sensitivity and $\beta$-cell glucose sensitivity from the response to intravenous glucose. J. Clin. Invest. 68:1456-1467.

24. Diamond, M. P., D. C. Somonson, and R. A. DeFronzo. 1989. Menstrual cyclicity has a profound effect on glucose homeostasis. Fertil. Steril. 52:204208.

25. Valdes, C. T., and K. E. Elkind-Hirsch. 1991. Intravenous glucose tolerance test-derived insulin sensitivity changes during the menstrual cycle. J. Clin Endocrinol. Metab. 72:642-646.

26. Byrne, M. M., J. Sturis, and K. S. Polonsky. 1995. Insulin secretion and clearance during low-dose graded glucose infusion. Am. J. Physiol. 268 (Endocrinol. Metab. 31):E21-E27.

27. Byrne, M. M., J. Sturis, K. Clement, N. Vionnet, M. E. Pueyo, M. Stoffel, J. Takeda, P. Passa, D. Cohen, G. I. Bell, G. Velho, P. Frougel, and K. S. Polonsky. 1994. Insulin secretory abnormalities in subjects with hyperglycemia due to glucokinase mutations. J. Clin. Invest. 93:1120-1130.

28. Sturis, J., E. Van Cauter, J. D. Blackman, and K. S. Polonsky. 1991. Entrainment of pulsatile insulin secretion by oscillatory glucose infusion. J. Clin. Invest. 87:439-445.

29. Shapiro, E. T H Tillil, K. S. Polonsky, A. H Rubenstein, and E. Van Cauter. 1988. Oscillations in insulin secretion during constant glucose infusion in normal man: relationship to changes in plasma glucose. J. Clin. Endocrinol. Metab. 67:307-314.

30. Morgan, C. R., and A. Lazarow. 1963. Immunoassay of insulin: two antibody system: plasma insulin levels of normal, subdiabetic and diabetic rats. Diabetes. 12:115-126.

31. Faber, O. K., C. Binder, J. Markussen, L. G. Heding, V. K. Naithani, H. Kuzuga, P. Blix, D. L. Horwitz, and A. H. Rubenstein. 1978. Characterization of seven C-peptide antisera. Diabetes. 27(Suppl. 1):170-177.

32. Barnes, R. B., R. L. Rosenfield, S. Burstein, and D. A. Ehrmann. 1989. Pituitary-ovarian responses to nafarelin testing in the polycystic ovary syndrome. N. Engl. J. Med. 320:559-565.

33. Rosenfield, R. L., R. B. Barnes, J. F. Cara, and A. W. Lucky. 1990 Dysregulation of cytochrome $\mathrm{P} 450 \mathrm{c} 17 \alpha$ as the cause of polycystic ovary syndrome. Fertil. Steril. 53:785-791.

34. Moll, G. W., R. L. Rosenfield, and J. H. Helke. 1981. Estradiol-testosterone binding interactions and free plasma estradiol under physiological conditions. $J$. Clin. Endocrinol. Metab. 52:868-876.

35. Bergman, R. N. 1989. Lilly Lecture 1989 . Toward physiological understanding of glucose tolerance: minimal model approach. Diabetes. 38:1512-1527.

36. Kahn, S. E., R. L. Prigeon, D. K. McCulloch, E. J. Boyko, R. N. Bergman,

M. W. Schwartz, J. L. Neifing, W. K. Ward, J. C. Beard, J. P. Palmer, and D.

Porte. 1993. Quantification of the relationship between insulin sensitivity and B- cell function in human subjects. Evidence for a hyperbolic function. Diabetes. 42:1663-1672.

37. Van Cauter, E., F. Mestrez, J. Sturis, and K. S. Polonsky. 1992. Estimation of insulin secretion rates from C-peptide levels. Comparison of individual and standard kinetic parameters for C-peptide clearance. Diabetes. 41:368-377.

38. Eaton, R. P., R. C. Allen, D. S. Schade, K. M. Erickson, and J. Standefer 1980. Prehepatic insulin production in man: kinetic analysis using peripheral connecting peptide behavior. J. Clin. Endocrinol. Metab. 51:520-528.

39. Polonsky, K. S., J. Licinio-Paixao, B. D. Given, W. Pugh, P. Rue, J. Galloway, T. Karrison, and B. Frank. 1986. Use of biosynthetic human C-peptide in the measurement of insulin secretion rates in normal volunteers and type $I$ diabetic patients. J. Clin. Invest. 77:98-105.

40. Sturis, J., K. S. Polonsky, E. T. Shapiro, J. D. Blackman, N. M. O'Meara, and E. Van Cauter. 1992. Abnormalities in the ultradian oscillations of insulin secretion and glucose levels in type 2 (non-insulin-dependent) diabetic patients. Diabetalogia. 35:681-689.

41. Jenkins, G. M., and D. G. Watts. 1968. Spectral Analysis and Its Applications. Holden Day, San Francisco. 525 pp.

42. Sonnenberg, G., R. G. Hoffman, R. A. Mueller, and A. H. Kissebah. 1994 Splanchnic insulin dynamics and secretion pulsatilities in abdominal obesity. Diabetes. 43:468-477.

43. Peiris, A. N., R. A. Mueller, M. F. Struve, G. A. Smith, and A. H. Kissebah. 1987. Relationship of androgenic activity to splanchnic insulin metabolism and peripheral glucose utilization in premenopausal women. J. Clin. Endocrinol. Metab. 64:162-169.

44. Elkind-Hirsch, K. E., C. T. Valdes, and L. R. Malinak. 1993. Insulin resistance improves in hyperandrogenic women treated with Lupron. Fertil. Steril. 60:634-641.

45. Dunaif, A., G. Green, W. Futterweit, and A. Dobrjansky. 1990. Suppression of hyperandrogenism does not improve peripheral or hepatic insulin resistance in the polycystic ovary syndrome. J. Clin. Endocrinol. Metab. 70:699-704.

46. Ortiz, J., J. Sturis, M. Smith, A. Stoltz, and J. Halter. 1994. Glucose control of ultradian insulin secretory oscillations is impaired in elderly humans. Diabetes. 43(Suppl. 1). 774a (Abstr.).

47. Lillioja, S., D. M. Mott, J. K. Zadawadzki, A. A. Young, W. G. H. Abbott, W. C. Knowler, P. H. Bennett, P. Moll, and C. Bogardus. 1987. In vivo insulin action is familial characteristic in nondiabetic Pima Indians. Diabetes. 36:13291335.

48. Janssen, R. C., C. Bogardus, J. Takeda, W. C. Knowler, and D. B. Thompson. 1994. Linkage analysis of acute insulin secretion with GLUT-2 and glucokinase in Pima Indians and the identification of a missense mutation in GLUT-2. Diabetes. 43:558-563.

49. Henriksen, J. E., F. Alford, A. Handberg, A. Vaag, G. M. Ward, A. Kalfas, and $\mathrm{H}$. Beck-Nielsen. 1994. Increased glucose effectiveness in normoglycemic but insulin-resistant relatives of patients with non-insulin-dependent diabetes mellitus. J. Clin. Invest. 94:1196-1204.

50. O'Rahilly, S., R. S. Spivey, R. R. Holman, Z. Nugent, A. Clark, and R. C. Turner. 1987. Type II diabetes of early onset: a distinct clinical and genetic syndrome? Br. Med. J. 294:923-928.

51. Dunaif, A., K. R. Segal, D. R. Shelley, G. Green, A. Dobrjansky, and T. Licholai. 1992. Evidence for distinctive and intrinsic defects in insulin action in polycystic ovary syndrome. Diabetes. 41:1257-1266.

52. Ciaraldi, T. P., A. El-Roeiy, Z. Madar, D. Reichart, J. M. Olefsky, and S. S. C. Yen. 1992. Cellular mechanisms of insulin resistance in polycystic ovary syndrome. J. Clin. Endocrinol. Metab. 75:577-583. 